\title{
Prognostic Implications of Ischemic Mitral Regurgitation Following Non-ST-Segment Elevation Acute Myocardial Infarction

\section{Abstract}

Introduction: Ischemic mitral regurgitation (MR) is a common complication of acute myocardial infarction and has a negative impact on prognosis. However, few studies have been carried out on MR after non-ST-segment elevation acute myocardial infarction (NSTEMI).

Aim: Investigate the clinical predictors of ischemic MR and its impact on the outcome after 1st NSTEMI.

Methods: 40 consecutive patients were selected after a first NSTEMI. Each underwent echocardiography and coronary angiography during their hospital admission. Patients were divided into two groups according to the presence or absence of MR at echocardiography: Group I: 20 patients without MR, Group II: 20 patients with MR. The patients were followed up clinically for at least one year. The incidence of readmission for heart failure, unstable angina, reinfarction, or all combined (i.e, major adverse cardiac event [MACE]) was recorded.

Results: The patients' mean age was $59.62 \pm 10.97$ years and 67.5 $\%$ were male. They were followed-up for a median of 640.5 days. No significant differences between both groups regarding baseline data, cardiac isoenzymes, or revascularization ( $P>0.05$ ), but there was significantly increased number of diseased coronary arteries in MR group (P 0.04). LA diameter was significantly increased with decreased LVEF\% and increased wall motion abnormalities in MR group $((P<0.05)$. During follow-up period, more admissions for unstable angina were seen in patients with MR but with little significance $(P$ 0.05). Regarding MACE, a greater incidence was found in the MR group $(P<0.05)$. Using Kaplan-Meier curves, a long-term association

\begin{abstract}
Mohamed Abdou',
\end{abstract} Mohamed Arab'

1 Cardiology Department, Faculty of Medicine, Zagazig University, Egypt.

Contact information:

Mohamed Abdou.

\$mhmdabdou11@gmail.com

Mohamed Arab.

$\equiv$ drm.arab@yahoo.com 
of MACE with the presence of MR was found (P 0.04), and a higher grades of MR were associated with poor prognosis ( $P$ 0.05).

In conclusion: Ischemic MR yield poor prognosis. Thus, current MR should be carefully assessed after NSTEMI, and probably requires even more meticulous treatment including early revascularization and stricter follow-up than usual.

\section{Keywords}

Mitral regurgitation -Non-

ST-elevation myocardial infarction-prognosis

\section{About this subject}

It is well known through many studies the adverse prognosis of ischemic MR after acute coronary syndrome specially STEMI and just scarce studies address that effect after NSTEMI. We think that our study is the only one to choose patients documented to had no MR before NSTEMI.

This will add the importance to strongly handle any MR after acute coronary syndrome with careful attention to help decision making.

\section{Introduction}

Ischemic mitral regurgitation (MR) conveys adverse prognosis, doubling mortality after myocardial infarction (MI), in chronic heart failure, and after surgical or catheter revascularization [1, 2].

Not only patients with moderate to severe MR had a greater risk of mortality and worse prognosis [3] but also mildest grades of MR were associated with worse prognosis $[4,5]$ with a graded relationship between severity and reduced survival [6].

In fact, MR after MI was associated with a 3-fold increased risk of heart failure, regardless of age, sex, Killip class at admission, and ejection fraction [7]. Also, it has been reported that degenerative MR before infarction is an independent risk factor [8].

In general, previous studies have focused on STelevation myocardial infarction, during the short or medium term and ischemic MR [1, 4]. Few studies have addressed the role of functional MR in risk stratification in patients with NSTEMI during the long- term and even the short- term $[9,10,11]$.

Thus, we aimed to investigate the clinical predictors of ischemic MR and its impact on the outcome after $1^{\text {st }}$ NSTEMI.

\section{Patients and methods}

A total of 40 consecutive patients who mets the criteria of the study protocol were selected.

\section{Inclusion criteria}

- Admission to the coronary unit of our center for a first NSTEMI.

- All patients were scheduled for coronary angiography during their hospital admittion.

- Available echo-Doppler report before admission with no evidence for MR.

- Regular periodic follow-up for at least 1 year.

\section{Exclusion criteria}

- Valvular structural heart disease, mitral prosthesis.

- Hypertrophic cardiomyopathy.

- NYHA functional class III or IV.

- AF or kidney failure.

- Mechanical complications.

- Poor ultrasound window.

The diagnosis of NSTEMI was based on the criteria published by the European Society of Cardiology [12]. The medical record, laboratory findings, hospital course, and follow-up were meticulously collected. 


\section{Echocardiographic studies}

All patients underwent complete echo-Doppler evaluation within the $1^{\text {st }} 3$ days of admission. The machine used was GE Vivid 7 ultrasound system with $2.5 \mathrm{MHz}$ transducer. Images were taken while the patient supine or in the left lateral position, utilizing the two-dimensional (2-D), M-mode and Doppler echocardiographic techniques. Measurements included left atrial and ventricular diameters measured in the M-mode; left parasternal view. Left ventricular ejection fraction was calculated in 2D-mode, in the apical 2- and 4- chamber apical views, using the Simpson biplane method. Left ventricular regional systolic function was assessed by dividing the left ventricle into the 16-segment model, following the recommendations of the American Society of Echocardiography [13]. Wall motion for each segment was visually graded using both endocardial motion and wall thickness with a semiquantitative four-points scoring system. The sum of these individual segmental scores is divided by the total number of the interpretable 16 segments to obtain the total wall motion score index. Systolic pulmonary artery pressure was calculated in reference to tricuspid regurgitation [14].

Mitral valve anatomy and function were specifically studied. Mitral regurgitation and its grade were assessed using the color jet area, vena contracta width (VCW), and the proximal isovelocity surface area (PISA) method, as usually conducted in our laboratory. PISA method, validated and simplified, is in excellent agreement with the angiographic grade of mitral regurgitation $[15,16]$.

Thus, MR was quantified into 5 grades $(0=$ no MR; I = mild; II = mild to moderate; III = moderate; IV = severe). Patients were divided into two groups according to the presence or absence of MR:

Group I: 20 patients without MR, Group II: 20 patients with MR.

Patients with trivial MR were included in the group without MR.

\section{Angiographic studies}

Coronary angiography was performed to all patients using standard techniques. Significant coronary disease was defined by angiographic stenosis $\geq 70 \%$ in the epicardial coronary arteries and $\geq 50 \%$ in the left main coronary artery. The extent of coronary disease was characterized by 1-, 2-, or 3-vessel disease [17]. Catheterization and percutaneous or surgical revascularization were selected according to the criteria of the physicians in charge.

\section{Recorded events during follow-up}

The incidence of readmission for heart failure, unstable angina, reinfarction, or all combined (ie, the combined event or major adverse cardiac event [MACE]) was recorded.

Medical events as unstable angina, acute myocardial infarction or heart failure episode that required hospital readmission and were noted in the discharge report as one of the presumed causes of these admissions were recorded. Each event was recorded only once; for example, after a heart failure event, new episodes were not taken into account in the statistical analysis of MACEs. For all variables, the patient data were censored after the first event.

\section{Statistical analysis}

All the analyses were performed using a commercially available software package (IBM SPSS Statistics 22, USA). Baseline characteristics are expressed as mean \pm standard deviation for continuous variables and absolute number (proportions) for categorical variables. Comparisons between groups were made with Pearson's $x^{2}$ test for categorical variables and the t-test for continuous variables. In the analysis, MR was used as a categorical variable. Long-term follow-up survival curves for various groups were constructed using the Kaplan-Meier method, and comparisons were made using the log-rank test. Logistic regression and Cox's proportional hazards regression univariate analysis were used to select the variables associated with in-hospital and longterm events, respectively. 
A P-value of $<0.05$ was considered statistically significant [18].

\section{Results}

\section{Patients characteristics, coronary angiography and interventions in the 2 groups (Table 1)}

The study included 40 patients with NSTEMI for the $1^{\text {st }}$ time. The patients' mean age was $59.62 \pm 10.97$ years and $67.5 \%$ were male.They were divided into 2 groups according to the presence or absence of MR. There was no significant differences between the 2 groups regarding age, gender, available risk factors, troponin or creatine kinase-MB isoenzymes $(P>0.05)$. Also, no diffirences were found regarding revascularization before getting $1^{\text {st }}$ NSTEMI or even after that $(P>0.05)$, but there was significantly increased number of diseased coronary arteries in the group of NSTEMI patients with MR (P 0.04). Medical treatment at discharge was similar in both groups, including ACE-inhibitors, ARBs or B-blockers $(P>0.05)$.

\section{Initial echocardiographic parameters in the $\mathbf{2}$ groups (Table 2)}

Left atrial diameter was significantly increased in NSTEMI patients with MR $(P<0.001)$. Also, Left ventricular systolic function ( EF\%) was decreased in those patients with MR (P 0.04). The incidence of wall motion abnormalities (WMS \&WMSI) were greater in the group with MR $(P<0.05)$. No significant differences between the 2 groups were found regarding left ventricular end systolic and end diastolic diameters or transmitral Doppler ultrasound measurements, including $\mathrm{E}$ waves, $\mathrm{A}$ waves and $\mathrm{E} / \mathrm{A}$ ratios. Also, there was no significant differences between the 2 groups regarding systolic pulmonary arterial pressure $(P>0.05)$.

\section{Follow-up data in the $\mathbf{2}$ groups (Table 3)}

All patients were followed-up for a median of 640.5 days. No significant difference was found between
Table 1. Patients characteristics, coronary angiography and interventions.

\begin{tabular}{|c|c|c|c|}
\hline Parameter & $\begin{array}{l}\text { No MR } \\
\text { (N 20) }\end{array}$ & $\begin{array}{c}\text { MR } \\
(\text { N 20) }\end{array}$ & P-value \\
\hline $\operatorname{Age}(Y)$, mean $\pm S D$ & $61.4 \pm 11.71$ & $57.85 \pm 10.16$ & 0.31 \\
\hline Male, n (\%) & $13(65 \%)$ & $14(70 \%)$ & 0.500 \\
\hline Smokers & $11(55 \%)$ & $12(60 \%)$ & 0.500 \\
\hline Hypertension & $16(80 \%)$ & $15(75 \%)$ & 0.500 \\
\hline Diabetes melletus & $12(60 \%)$ & $13(65 \%)$ & 0.500 \\
\hline Dyslipidemia & $14(70 \%)$ & $16(80 \%)$ & 0.35 \\
\hline $\begin{array}{l}\text { Patients with } \\
\text { previous } \\
\text { revascularization }\end{array}$ & $5(25 \%)$ & $2(10 \%)$ & 0.20 \\
\hline $\begin{array}{l}\text { Developed Q- wave } \\
\text { in the acute phase }\end{array}$ & $4(20 \%)$ & $6(30 \%)$ & 0.35 \\
\hline $\begin{array}{l}\text { Peak creatine } \\
\text { kinase-MB }\end{array}$ & $20.52 \pm 15.93$ & $21.26 \pm 17.18$ & 0.88 \\
\hline $\begin{array}{l}\text { Peak cardiac } \\
\text { troponin-I }\end{array}$ & $5.30 \pm 5.42$ & $4.46 \pm 4.92$ & 0.61 \\
\hline $\begin{array}{l}\text { ACE-inhibitors } \\
\text { ARBs }\end{array}$ & $14(70 \%)$ & $10(50 \%)$ & 0.16 \\
\hline Vessel disease & $1(0-2)$ & $1.5(1-3)$ & 0.04 \\
\hline 1 vessel & $13(65 \%)$ & $14(70 \%)$ & 0.500 \\
\hline 2 vessels & $3(15 \%)$ & $5(25 \%)$ & 0.35 \\
\hline 3 vessels & $0(0 \%)$ & $1(5 \%)$ & 0.500 \\
\hline $\begin{array}{l}\text { Patients } \\
\text { revascularized } \\
\text { during admittion }\end{array}$ & $15(75 \%)$ & 19 (95\%) & 0.09 \\
\hline \multicolumn{4}{|c|}{$\begin{array}{l}\text { ACE: Angiotensin converting enzyme } \\
\text { ARBs: Angiotensin receptor blockers }\end{array}$} \\
\hline
\end{tabular}

Table 2. Initial Echocardiographic Parameters.

\begin{tabular}{|c|c|c|c|}
\hline Parameter & $\begin{array}{c}\text { No MR } \\
\text { (N 20) }\end{array}$ & $\begin{array}{c}\text { MR } \\
\text { (N 20) }\end{array}$ & P-value \\
\hline LAD (cm) & $3.33 \pm 0.464$ & $4.09 \pm 0.675$ & 0.000 \\
\hline $\mathrm{ESD}(\mathrm{cm})$ & $3.745 \pm 0.480$ & $3.925 \pm 0.372$ & 0.15 \\
\hline EDD (cm) & $5.32 \pm 0.698$ & $5.38 \pm 0.510$ & 0.73 \\
\hline LVEF \% & $56.55 \pm 6.88$ & $51.85 \pm 7.49$ & 0.04 \\
\hline E/A ratio & $1.01 \pm 0.359$ & $1.09 \pm 0.501$ & 0.58 \\
\hline SPAP $(\mathrm{mmHg})$ & $24.25 \pm 7.188$ & $29.6 \pm 11.16$ & 0.08 \\
\hline WMS & $18.25 \pm 1.45$ & $19.50 \pm 1.67$ & 0.016 \\
\hline WMSI & $1.14 \pm 0.09$ & $1.22 \pm 0.10$ & 0.015 \\
\hline
\end{tabular}

LAD: Left atrial diameter, ESD:End systolic diameter, EDD: End diastolic diameter, LVEF: Left ventricular ejection fraction, SPAP: Systolic pulmonary artery pressure, WMS: Wall motion score, WMSI: Wall motion score index 
Table 3. Follow-up data in the 2 groups.

\begin{tabular}{|c|c|c|c|}
\hline Parameter & $\begin{array}{l}\text { No MR } \\
(\text { N 20) }\end{array}$ & $\begin{array}{c}\text { MR } \\
(\text { N 20) }\end{array}$ & P-value \\
\hline $\begin{array}{l}\text { Follow-up } \\
\text { period }(d)\end{array}$ & $606.10 \pm 227.57$ & $594.10 \pm 277.74$ & 0.80 \\
\hline $\begin{array}{l}\text { Unstable } \\
\text { angina }\end{array}$ & $0(0 \%)$ & $4(20 \%)$ & 0.05 \\
\hline $\begin{array}{l}\text { Myocardial } \\
\text { infarction }\end{array}$ & $2(10 \%)$ & $2(10 \%)$ & 0.69 \\
\hline Arrythmia & $3(15 \%)$ & $5(25 \%)$ & 0.35 \\
\hline $\mathrm{CHF}$ & $0(0 \%)$ & $2(10 \%)$ & 0.24 \\
\hline MACE & $2(10 \%)$ & $8(40 \%)$ & 0.032 \\
\hline \multicolumn{4}{|c|}{$\begin{array}{l}\text { CHF :Congestive Heart Failure, MACE: Major Adverse } \\
\text { Cardiac Events }\end{array}$} \\
\hline
\end{tabular}

the 2 groups regarding the follow-up period $(P>$ 0.05). Recorded clinical events during follow-up period showed more admissions for heart failure and unstable angina in patients with MR but did not reach statistical significance for heart failure $(P$ $>0.05$ ) with little significance for unstable angina (p 0.05).

Figure 1: Kaplan-Meier survival analysis of MACEfree survival in NSTEMI patients without $M R$ versus with $M R$.

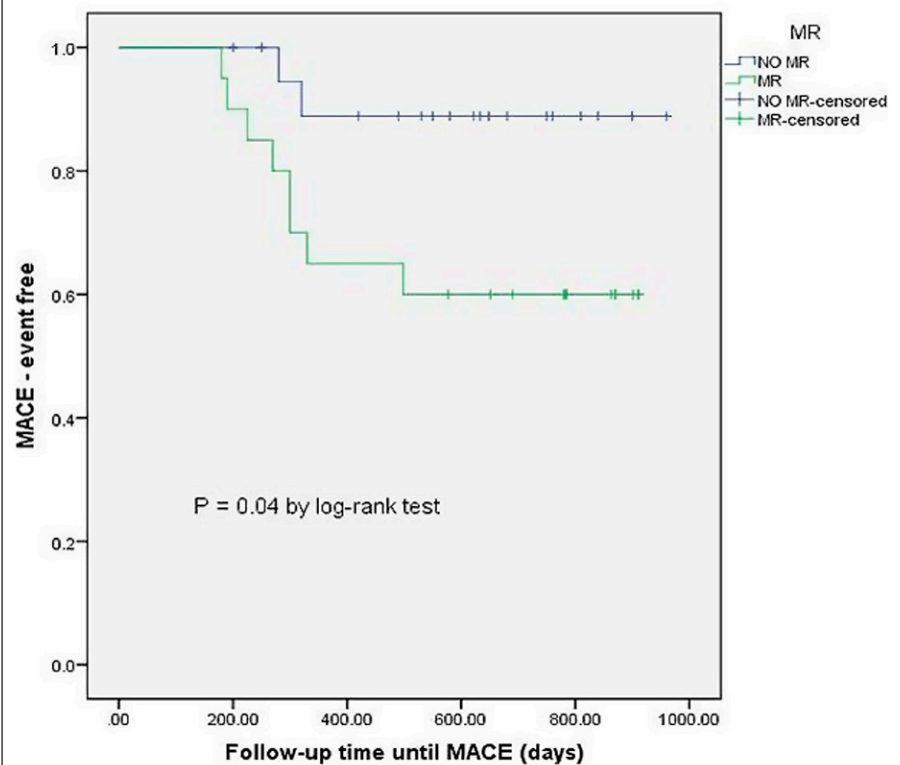

MACE: major adverse cardiac event, MR: mitral regurgitation, NSTEMI: non- ST-segment elevation myocardial infarction.
No differences were observed between both groups regarding readmissions for acute myocardial infarction, with or without $\mathrm{Q}$-wave $(\mathrm{P}>$ 0.05). Finally, regarding composite events (MACE), a greater incidence was found in the MR group $(P<0.05)$.

Kaplan-Meier curves and the log-rank test showed the long-term association of MACE with the presence of MR ( $p$ 0.04) (Figure 1), and when used to compare long-term prognosis in one group without MR or with MR grade I against the other group of patients with higher grades of $M R(\geq I)$, it demonstrated that a higher grades of MR were associated with poor prognosis ( $P$ 0.05) (Figure 2).

The multivariate (cox) analysis was conducted and included all variables. WMSI was the only factor found to be associated with the appearance of MACE (HR0.00, 95\% Cl 1.06-1.19, P 0.01).

Figure 2: Kaplan-Meier survival analysis of MACE-free survival in NSTEMI patients with high MR grade versus low MR grade.

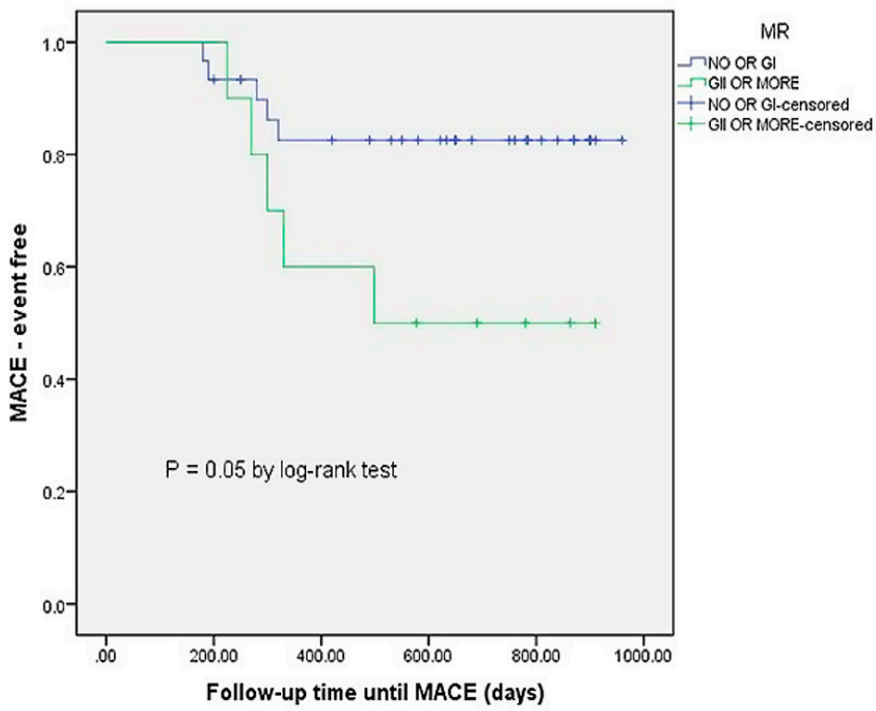

MACE: major adverse cardiac event, MR: mitral regurgitation, NSTEMI: non- ST-segment elevation myocardial infarction 


\section{Discussion}

Functional ischemic MR is a common finding following acute coronary syndrome [19]. Studies have reported its incidence from $9-13 \%$ using cardiac catheterization $[20,21,22]$ to $50 \%$ in echocardiographic studies $[6,7,22]$.

The appearance of mitral regurgitation (MR) in the setting of myocardial ischemia could be due to discrepancy of tethering force and closing force or papillary muscle displacement owing to remodeled left ventricle [23].

MR increases LV remodeling and volume in the post-MI setting with aggravation of the morphological, functional, cellular, and extracellular stigmata of remodeling. It can cause as well as result from LV remodeling and can therefore potentially exacerbate it in a vicious cycle spiraling down to cardiac failure unless there is intervention [24, 25].

So, detecting and quantifying ischemic mitral regurgitation is necessary since its presence plays an essential role in post-MI risk stratification [10].

This study investigate the clinical predictors and the prognostic significance of ischemic MR on outcome, specifically after a first episode of NSTEMI. Data were analyzed from patients who had cardiovascular complications of sufficient clinical severity to require re-hospitalization.

The study population was basically homogeneous, even in age, sex, smoking and the presence of DM and this was discordant with many previous studies reported that acute ischemic MR is seen with increased frequency in elderly, women and nonsmokers $[7,20]$ and this principally may be due to small our sample size.

MR was assessed in all patients during early hospital admission taking into account potential reversible myocardial dysfunction (stunning or hibernation) after infarction which may affect the genesis of MR.

It is well known that MR alone is an independent factor of poor prognosis $[5,7,8,10]$ and when associated with a myocardial infarction prognosis is even worse $[5,8,10]$.
In our study, a higher rate of composite MACE was observed, during follow-up in patients in whom ischemic MR was detected in the first echocardiogram during the acute phase of NSTEMI. Also, long-term outcome analyses indicated that composite MACE was greater in the high grade MR group than in the low grade MR group ( $p$ 0.05), and this was concordant with the study done by Grigioni et al, 2001 [6] and Cho et al 2013 [11] that showed a graded relationship between MR severity and outcome.

There were no significant differences in size of the infarction, as measured by creatine kinase and troponin I levels, in spite of which LVEF was significantly worse in the MR group; may by due to increased area of ischemia (stunning) as noted by significantly higher WMS and WMSI in the MR group.

Nevertheless, regression analysis revealed that WMS and WMSI, not MR, were the only factors significantly affect MACE at short and long -term outcome, indicating that MR itself was not an independent predictor of MACE in patients with NSTEMI, and MR could be a crude single predictor of future adverse cardiac events.

On the other hand, WMSI, a marker of regional LV dysfunction, provide powerful prognostic information after acute myocardial infarction either at short -term or long- term outcome and its predictive power is even greater than $\operatorname{LVEF} \%[26,27]$.

The greater number of diseased vessels in the MR group, in addition to being associated with MR, could have had an effect on the increased number of ischemic events, such as unstable angina, although little significance ( $p$ 0.05), during follow-up.

In spite that the role of ischemic MR in the development of heart failure after infarction has been addressed by many authers $[20,28,29]$, there was no significant difference between patients with ischemic MR and those without regarding the development of heart failure during follow up, again, may be due to the small sample size in our study. 
Diastolic function was not specifically explored, although some key parameters were analyzed in its study, such as left atrial diameter and transmitral peak $E$ and $A$ velocities. The E/A ratio did not indicate statistically significant differences between the 2 groups.

For our knowledge, our study may be the $1^{\text {st }}$ study to choose patients without MR prior to infarction to avoid an additional negative prognostic factor and this, on the other hand, affect number of patients in the study.

The limitations of this study would be 1) small sample size, 2) lack of echocardiographic followup of $M R, 3)$ no available data to compare the effect of early versus late coronary intervention, 4) treatment during follow-up was not analyzed, but, on the other hand, patients were treated according to the norms followed in our institution in recent years, and so the results of the study may reflect the conditions of daily clinical practice, 5) MR was not assessed during coronary angiography.

In conclusion, The presence of MR after a first NSTEMI adds prognostic significance to other known negative factors. The presence and degree of MR confer a worse long-term prognosis to patients after a first NSTEMI. According to American College of Cardiology (ACC)/American Heart Association (AHA) guidelines for UA/NSTEMI, initial invasive strategy could be indicated in the setting of signs/ symptoms of heart failure or new/worsening mitral regurgitation [30]. Thus, the presence of MR should be carefully assessed in every patient after an NSTEMI, and probably requires even more meticulous treatment and stricter follow-up than usual.

\section{References}

1. Bursi F, Enriquez-Sarano M, Jacobsen SJ, Roger VL. Mitral regurgitation after myocardial infarction: a review. Am J Med. 2006; 119: 103-12.

2. Levine RA, Schwammenthal E. Ischemic mitral regurgitation on the threshold of a solution: from paradoxes to unifying concepts. Circulation. 2005; 112: 745-58.
3. Hickey MS, Smith LR, Muhlbaier LH, Harrell FE Jr, Reves JG, Hinohara $T$, et al. Current prognosis of ischemic mitral regurgitation. Implications for future management. Circulation. 1988; 78: 151-9.

4. Lamas GA, Mitchell GF, Flaker GC, Smith SC Jr, Gersh BJ, Basta $L$, et al. Clinical significance of mitral regurgitation after acute myocardial infarction. Survival and Ventricular Enlargement Investigators. Circulation. 1997; 96: 827-33.

5. Feinberg MS, Schwammenthal E, Shlizerman L, Porter A, Hod $H$, Friemark $D$, et al. Prognostic significance of mild mitral regurgitation by color Doppler echocardiography in acute myocardial infarction. Am J Cardiol. 2000; 86: 903-7.

6. Grigioni F, Enriquez-Sarano M, Zehr KJ, Bailey KR, Tajik AJ. Ischemic mitral regurgitation: long-term outcome and prognostic implications with quantitative Doppler assessment. Circulation. 2001; 103: 1759-1764.

7. Bursi F, Enriquez-Sarano M, Nkomo VT, Jacobsen SJ, Weston SA, Meverden RA, et al. Heart failure and death after myocardial infarction in the community: the emerging role of mitral regurgitation. Circulation. 2005; 111: 295-301.

8. Zamorano J, de Isla LP, Oliveros L, Almeria C, Rodrigo JL, Aubele $A$, et al. Prognostic influence of mitral regurgitation prior to a first myocardial infarction. Eur Heart J. 2005; 26: 343-9.

9. Núñez Gil I J, de Isla LP, García-Rubira J C, Fernández-Ortiz A, et al. Ischemic Mitral Regurgitation and Non-ST-Segment Elevation Acute Myocardial Infarction: Long-Term Prognosis. Rev Esp Cardiol. 2009; 62 (11): 1267-75.

10. de Isla LP, Zamorano J, Quezada M, Almeria C, et al. Prognostic significance of functional mitral regurgitation after a first nonST-segment elevation acute coronary syndrome. Eur Heart J. 2006; 27: 2655-2660.

11. Cho JY, Jeong $M H$, Ahn $Y$, Jeong $H C$, et al. Different impact of mitral regurgitation on clinical outcomes according to timing of percutaneous coronary intervention in patients with non-ST segment elevation myocardial infarction. Inter J Cardiol.2013; 168(5), 4872-74.

12. Bertrand M, Simoons M, Fox K, Wallentin L, Hamm C, McFadden $E$, et al. Management of acute coronary syndromes in patients presenting without persistent ST-segment elevation.The Task Force on the Management of Acute Coronary Syndromes of the European Society of Cardiology. Eur Heart J. 2002: 1809-40.

13. Schiller N, Shah P, Crawford M, DeMaria A, Devereux R, Feigenbaum $\mathrm{H}$, et al. Recommendations for quantitation of the left ventricle by two-dimensional echocardiography. American Society of Echocardiography Committee on Standards, Subcommittee on Quantitation of Two Dimensional Echocardiograms. J Am Soc Echocardiogr.1989; 2: 358-67.

14. Berguer M, Haimowitz A, Van T, Berdoff R, Goldberg E. Quatitative assesment of pulmonary hypertension in patients with tricuspid regurgitation using continuous wave Doppler ultrasound. J Am Coll Cardiol.1985; 6: 359-65. 
15. Enriquez-Sarano M, Miller FJ, Hayes S, Bailey K, Tajik A, Seward J. Effective mitral regurgitant orifice area: clinical use and pitfalls of the proximal isovelocitysurface area method. J Am Coll Cardiol. 1995; 25: 703-9.

16. Moya J, Catalan M, Garcia-Lledo A, Pey J, Barcia F, Asin E. A semiquantitative method based on proximal convergence zone to estimate the severity of the mitral regurgitation: design and clinical application. Eur J Echocardiogr. 2001; 2: 163-9.

17. Bart B, Shaw L, McCants CJ, Fortin D, Califf R, O'Connor C. Clinical determinants of mortality in patients with angiographically diagnosed ischemic or nonischemic cardiomyopathy. J Am Coll Cardiol. 1997; 30: 1002-8

18. Metha $C$, Patel N. Exact logistic regression: theory and examples. Stat Med 1995; 14: 2143-60.

19. Gillinov AM, Wierup PN, Blackstone EH, Bishay ES, Cosgrove DM, White J, et al. Is repair preferable to replacement for ischemic mitral regurgitation? J Thorac Cardiovasc Surg 2001; 122: 1125-41.

20. Grigioni F, Detaint D, Avierinos JF, Scott C, Tajik J, EnriquezSarano M. Contribution of ischemic mitral regurgitation to congestive heart failure after myocardial infarction. J Am Coll Cardiol. 2005; 45: 260-7.

21. Lehmann KG, Francis CK, Dodge HT. Mitral regurgitation in early myocardial infarction. Incidence, clinical detection, and prognostic implications. TIMI Study Group. Ann Intern Med. 1992; 117: 10-7

22. Barzilai B, Davis VG, Stone PH, Jaffe AS. Prognostic significance of mitral regurgitation in acute myocardial infarction. The MILIS study group. Am J Cardiol. 1990; 65: 1169-75.

23. Otsuji $Y$, Hand Schumacher MD, Schwammenthal E, et al. Insights from three dimensional echocardiography into the mechanism of functional mitral regurgitation: direct in vivo demonstration of altered leaflet tethering geometry.Circulation. 1997; 96: 1999-2008.

24. Beeri R, Yosefy C, Guerrero JL, Nesta F, Abedat S, Chaput M, del Monte F, Handschumacher MD, Stroud R, Sullivan S, Pugatsch T, Gilon D, Vlahakes GJ, Spinale FG, Hajjar RJ, Levine RA. Mitral regurgitation augments post-myocardial infarction remodeling failure of hypertrophic compensation. J Am Coll Cardiol. 2008; 51: 476-486.

25. Szymanski C, Bel A, Cohen I, Touchot B, et al ;for the Leduca Foundation MITRAL Transatlantic Network.Comprehensive Annular and Subvalvular Repair of Chronic Ischemic Mitral Regurgitation Improves Long-Term Results With the Least Ventricular Remodeling. Circulation. 2012; 126: 2720-2727.

26. Møller JE, Hillis GS, Oh JK, Reeder GS, Gersh BJ, Pellikka PA. Wall motion score index and ejection fraction for risk stratification after acute myocardial infarction.Am H J. 2006; 151 (2): 419425.

27. Salehi N, Maleki M, Noohi F, Sadeghpour A, et al. Left Ventricular Wall Motion Score Index as an Early Predictor of Hemodynamic State after Myocardial Infarction.Iranian H J. 2007; 8 (2): 16-21.
28. Carabello BA. The current therapy for mitral regurgitation. J Am Coll Cardiol. 2008; 52: 319-26.

29. Amigoni M, Meris A, Thune JJ, Mangalat D, Skali H, Bourgoun M, et al. Mitral regurgitation in myocardial infarction complicated by heart failure, left ventricular dysfunction, or both: prognostic significance and relation to ventricular size and function. Eur Heart J. 2007; 28: 326-33.

30. Jneid H, Anderson JL, Wright RS, et al. 2012 ACCF/AHA focused update of the guideline for the management of patients with unstable angina/non-ST-elevation myocardial Infarction (updating the 2007 guideline and replacing the 2011 focused update): a report of the American College of Cardiology Foundation/American Heart Association Task Force on Practice Guidelines. J Am Coll Cardiol. 2012; 60: 645-81.

\section{Comment on this article:}

\section{(f) $B$ in $8+\mathbf{S} P$}

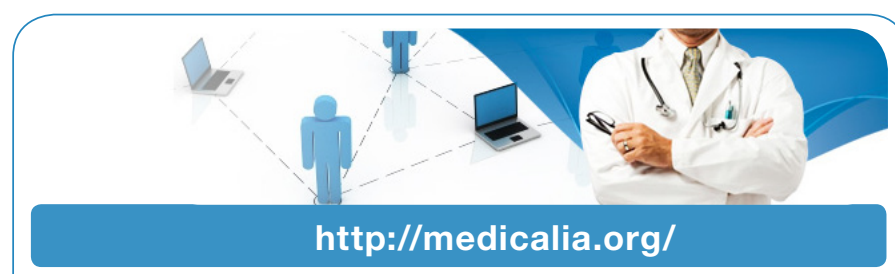

Where Doctors exchange clinical experiences, review their cases and share clinical knowledge. You can also access lots of medical publications for free. Join Now!

\section{Publish with iMedPub}

http://www.imed.pub

International Archives of Medicine is an open access journal publishing articles encompassing all aspects of medical science and clinical practice. IAM is considered a megajournal with independent sections on all areas of medicine. IAM is a really international journal with authors and board members from all around the world. The journal is widely indexed and classified Q1 in category Medicine. 